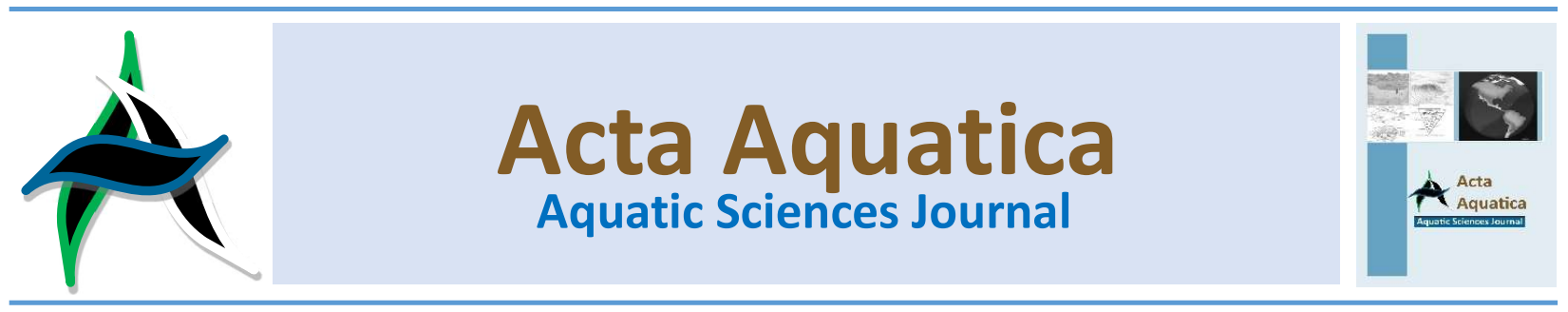

\title{
The rhetorical blue economy in Bangladesh: Analyzing the inborn regulatory bottlenecks
}

\author{
Md. Mizanur Rahman ${ }^{a *}$ \\ ${ }^{a}$ Bangladesh Public Administration Training Centre, Dhaka, Bangladesh
}

\begin{abstract}
This study's overreaching objective was to assess the suitability and applicability of the existing legal and institutional framework for managing the coastal and marine resources in Bangladesh. Together with, the fundamental challenges faced by the artisanal and smallscale fishers in Bangladesh were critically scrutinized. The study revealed that the regulatory framework in Bangladesh is characterized by jurisdictional overlapping followed by the conflict of interests among the public institutes, which originated from the aged and fragmented laws and ambiguous business allocation; consequently, the artisanal and small-scale fishers suffer a lot. The local government and community's right to resource management remains fuzzy. Bangladesh can enact new sectoral laws followed by business reallocation for the line ministries. The study will help policymakers identify the bottlenecks rooted in the existing regulatory and institutional framework.
\end{abstract}

Keywords: Coastal and Marine Resource; Jurisdictional Overlapping; Conflict of Interests; Marine Governance; Artisanal Fishers

\section{Introduction}

Bangladesh is located in the north-east corner of the Bay of Bengal and blessed with living and non-living resources (FAO, 2014). The Bay of Bengal's living resources comprised of fisheries, pearls, corals, mangroves, planktons, seaweeds, and other ecosystem services (Ahmed and Glaser, 2016; Islam and Shamsuddoha, 2018). The Sundarbans mangrove also supplies essential ecosystem services like fish, crabs, turtles, shrimp, honey, medicinal plants, Nypa palm leaf, wax, wood, white mangrove date palm, and fodder. Extraction, exploration, management, and conservation of both living and non-living resources of the Bay can contribute a lot to Bangladesh's economy (Hasan et al., 2018). The Bay of Bengal can offer considerable opportunities to resolve the challenges originating from the climate changes in the coastal areas (Giménez et al., 2014). Bangladesh confronts both incremental locals (Rahman et al., 2009) and climatic stressors (Rahman 2020) to protect its natural resources. On the other hand, sustainable resource management may generate decent works and bring a tangible change to the people residing in the coastal zones and across the country (Ahmed and Rahman, 2020; Hussain et al., 2017, 2018). The potential of the marine and coastal resources has not been identified so far.

Several studies found that the implementation level's institutional mechanisms are not adequately functional to flourish coastal and marine fisheries in Bangladesh (Islam, 2012; Alam et al., 2021; Shamsuzzaman and Islam, 2018; Shamsuzzaman et al., 2017a, b; Rahman et al. 2020; Rahman and

${ }^{*}$ Corresponding author: Director (Research and Development) Bangladesh Public Administration Training Centre

Dhaka 1343, Bangladesh

E-mail:mizan_peroj@yahoo.com

Phone: +88027746606
Alam 2020). Few old laws, especially inland laws, provide legal frameworks for fisheries management, which are not appropriately enforced for multiple reasons. The existing legal framework has led to "sector-by-sector" or "use-by-use" management practices. Diversely, the institutional mechanism, marine governance, stakeholder engagement, and coordination among different players are not clearly defined (Shamsuzzaman et al., 2017a; Rahman et al., 2020; Rahman and Alam 2020). Marine growth unquestionably depends on the connectivity among the terrestrial, freshwater, and marine realms. Therefore, a comprehensive study on coastal and marine resource management regulatory regimes in Bangladesh, considering both legal and institutional arrangements, has become indispensable. Thus, the study aims at analyzing the legal and institutional frameworks embedded with blue growth. This analysis will help in the identification of the knowledge gap and existing challenges. The study will immensely contribute to pinpointing the narrow and broad interfaces, constraints, and diffused connections among institutions from top to bottom.

The artisanal and small-scale fisheries face significant challenges that emerge from a policy implementation gap and weak law enforcement (Billah et al., 2018). The proportion of artisanal and small-scale fishers show a declining trend decreasing at an alarming rate due to lack of an integrated and holistic regulatory and institutional framework, which propagate a distorted market chain, climate vulnerabilities, and hegemony of the commercial fishers (Alam et al., 2021). This vulnerable group is becoming "left behind the group" by losing their income. The study also examined the fishers' challenges, notably artisanal and small-scale, to make policy interventions.

Bangladesh has taken several initiatives towards fortifying the institutional structures for harnessing the full utilization of marine-based potential resources eyeing on SDG 14 (Table 1). 
Table 1

List of the institutional initiatives for trapping coastal and marine resources in Bangladesh (Bdgov, 2020)

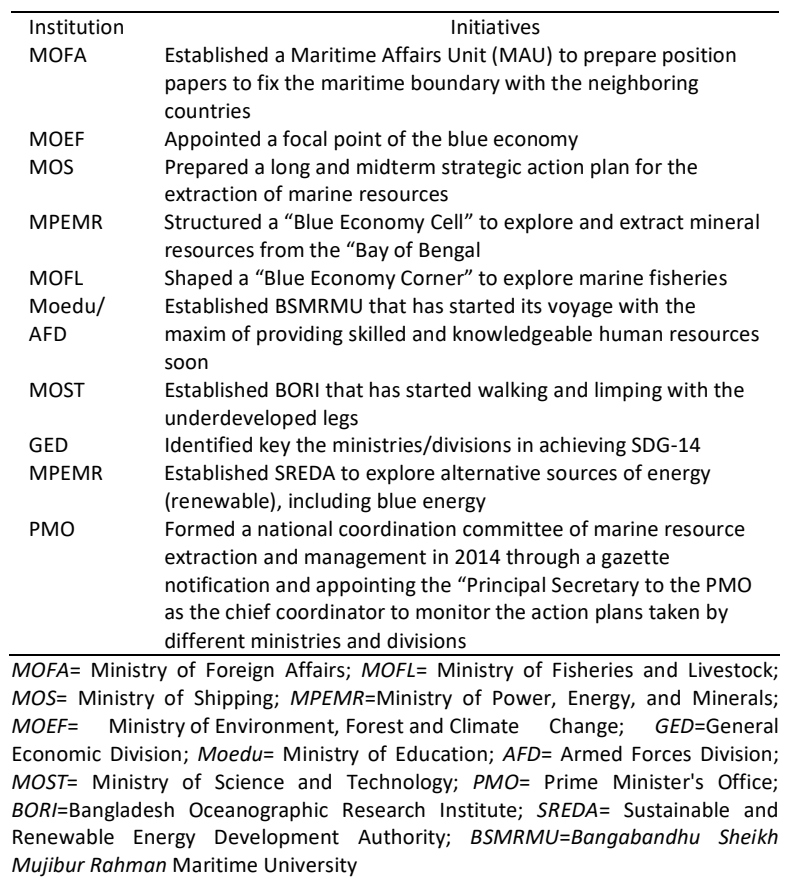

\section{Materials and Methods}

The study collected both primary and secondary data for the period from November 2018 to April 2020. Secondary data regarding the relevant Acts, Ordinances, and Rules relating to Bangladesh's marine resource management and sustainability were analyzed to develop background information.

\subsection{Primary data collection}

The primary data collection followed a mixed approach, including workshops, case studies, personal and key informant interviews (KKIs). The personal interview is considered the highest appreciated data collection approach in qualitative research (Gill et al., 2008). The semi-structured interview has no strict guidelines, depending on how the interviewee responds to the researcher's questions. The interviewee is comfortable with semi-structured interviews compared to the structured interview (Stuckey, 2013). Despite having a set of questions, the interviewees' response gives the researcher the flexibility of asking more supplementary questions than the initially drafted questionnaire. For this reason, the scholar prefers semistructured in-depth interviews for qualitative researchers (DiCicco-Bloom and Crabtree, 2006). Workshops, a research approach, cater a platform for a researcher in spotting, articulating, and scrutinizing poorly-defined or fuzzy challenges in the research domain (Ørngreen and Levinsen, 2017). KII technique helps the researcher who faces confusion in concluding and feels the need for experts' opinions (Ali et al., 2013). On the other hand, a case study is considered an affordable technique to gain a big picture idea of a complicated situation and allows for new and unforeseen issues to emerge (Harrison et al., 2017).

A national consultation workshop was held in Dhaka, incorporating ministries, research, training, educational institutes, and civil society. The participants were divided into two thematic groups: legal and institutional. The first group identified the fundamental laws along with their mottos and weaknesses. The second group found the line ministries and divisions having stakes directly and indirectly in marine and environmental management. They also scrutinized the respective mandates from the "Rules of Business 1996" and overlapping jurisdictional areas. Two divisional workshops were held in Khulna and Barishal, where approximately 50-60 participants were present in each. The divisional workshops' purposes were to identify the causal factors of non-compliance with laws and conflict of interests. All of the groups were requested to come up with solutions for overcoming the challenges.

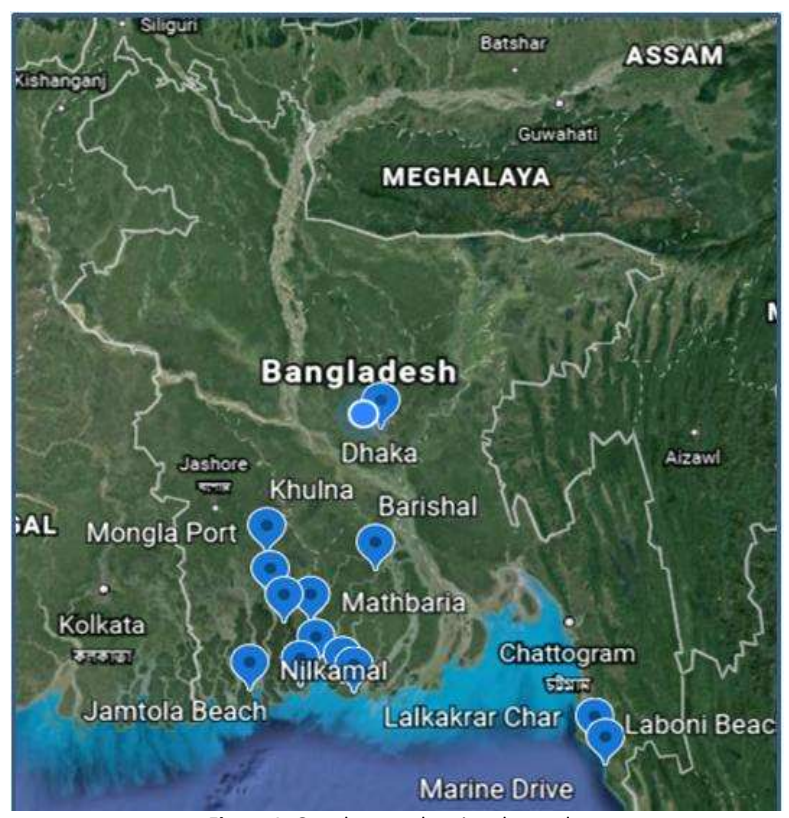

Figure 1: Google map showing the study areas

Three Focus Group Discussions (FGDs) were done at Bangladesh Oceanographic Research Institute, Marine Fisheries Academy, and Bangladesh Marine Academy, taking 5-8 respondents in each to understand the coordination mechanism among training and research institutes. In addition, seven case studies were done at Andharmanik, Nilkamal, Jamtola Beach, Mongla Port, Lalkakrar Char, Laboni beach, and Cox's BazarTeknaf Marine Drive to generate an idea about the coordination mechanism and management practices at the operational level (Figure 1). A total number of 120 individuals were interviewed by using a semi-structured questionnaire at Jhaliaghata (Patharghata sub-district), Boromasua (Mathbaria sub-district), and Mohipur (Kalapara sub-district) to identify the critical challenges of the artisanal and small-scale fishers. The questionnaire was prepared in the Bengali language, and then it was translated into English. During the consultation, talking in the mother tongue helps establish trust (Zhang and Guttormsen, 2016). A total number of 20 key informants, including academicians and line experts, were interviewed to identify the potential resources.

\subsection{Data analysis}

The content analysis was done considering its uniqueness, which supports qualitative (Dooley, 2016) and quantitative research (Krippendorf, 2004; Neuendorf, 2002; Spencer et al., 2003) in an inductive and deductive way. The collected data was coded into different categories and variables. The study preferred a manifest content analysis rather than a latent content analysis to reflect the respondents' total views avoiding biases (Berg, 2009). Four stages: de-contextualization, 
re-contextualization, categorization, and compilation, were followed in the content analysis (Bengtsson, 2016).

\section{Result and Discussion}

\subsection{The legal framework}

The respondents identified a total number of 19 laws that support marine resource management and sustainability directly or indirectly (Table 2). Article $18 \mathrm{~A}$ of the Constitution, without keeping any specific provisions, upholds the aspiration of sustainability of natural resources. This section was included in the "Fundamental Principles of the State Policy," which is judicially non-enforceable. "Territorial Waters and Maritime Zones Act, 1974" zoned the Bay of Bengal, discounting the concept of marine governance and not accrediting any specific ministry or department as the custodian of this law, though MOFA serves the purpose. The drafted "Bangladesh Maritime Zones Act, 2018" is an amendment of the act mentioned above, approved by the cabinet but not ratified as a bill through the parliamentary process. This draft also underlines the determination of the maritime zones and control of criminal activities. Therefore, the concept of marine governance has not been flourished in Bangladesh.

Table 2

List of key laws identified by the respondents

\begin{tabular}{cl}
\hline SL & \\
1 & The Constitution of the People's Republic of Bangladesh \\
2 & The Territorial Waters and Maritime Zones Act, 1974 \\
3 & Bangladesh Maritime Zones Act, 2018 (Draft) \\
4 & The Marine Fisheries Ordinance, 1983 \\
5 & The Protection and Conservation of Fish Rules, 1985 \\
6 & The Bangladesh Shipping Corporation Act, 2017 \\
7 & The Bangladesh Merchant Shipping Ordinance, 1983 \\
8 & The Bangladesh Flag Vessels (Protection) Ordinance, 1982 \\
9 & The Bangladesh Ship Recycling Act, 2018 \\
10 & The Bangladesh Oceanographic Research Institute Act, 2015 \\
11 & The Bangladesh Oil, Gas and Mineral Corporation Ordinance, 1985 \\
12 & The Sustainable and Renewable Energy Development Authority Act, \\
& 2012 \\
13 & Weather Act 2018 \\
14 & The protected areas of tourism and special tourism zone Act 2010 \\
15 & Bangladesh Water Act 2013 \\
16 & State Acquisition and Tenancy Act 1950 \\
17 & Bangladesh Environment Conservation Act 1995 \\
18 & Wildlife (Conservation and Security) Act 2012 \\
19 & Ecologically Critical Area Management Rules 2016 \\
\hline
\end{tabular}

"Bangladesh Merchant Shipping Ordinance, 1983" and "Bangladesh Flag Vessels (Protection) Ordinance 1982" and "Bangladesh Ship Recycling Act, 2018" entrusted MOS to administer maritime shipping and shipyard industry. Nonetheless, shipping-related laws are not accommodative with international conventions.

Marine Fisheries Ordinance, 1983" empowered MOFL to manage marine including high sea fisheries; in contrast, "Wildlife (Conservation and Security) Act, 2012" empowered the Ministry of Environment, Forest and Climate change (MOEF) to regulate the protected areas, including their resources. Interestingly, the "Bangladesh Merchant Shipping Ordinance, 1983" entitled MOS to register fishing vessels. Hence, Marine Fisheries are intersected by 03 ministries, which cause a conflict of interests and an obstacle in marine fisheries development in Bangladesh. "The Protection and Conservation of Fish Rules, 1985" underlines freshwater fisheries by downplaying the marine realm.

Similarly, MOEF also controls Marine tourism in the protected areas being empowered by the "Wildlife (Conservation and Security) Act, 2012". Contradictorily, the "State Acquisition and Tenancy Act 1950" authorized the Deputy Commissioner
(DC) of a district on behalf of the Ministry of Land (Minland) to maintain the rights in and over land and water. Hence, tourism in non-protected areas is managed by the district administration. "The protected areas of tourism and special tourism zone Act, 2010" authorized the Ministry of Civil Aviation and Tourism (MOCAT), the nodal institute, to regulate tourism. Likewise, this sector faces an onslaught of overlapping and underlapping jurisdictions and cannot move forward. Differently, "Ecologically Critical Area Management Rules, 2016" provided some authority to $M O E F$ in land management, which has created a conflict of interest with Minland.

The "Bangladesh Oil, Gas and Mineral Corporation Ordinance, 1985" entrusted MPEM to explore, extract and sell crude oil, natural gas, and mineral resources. The "Sustainable and Renewable Energy Development Authority Act, 2012" entitled this ministry to explore non-traditional renewable energy sources. The study revealed that only the "Territorial Waters and Maritime Zones Act, 1974"; "Marine Fisheries Ordinance, 1983"; "Bangladesh Flag Vessels (Protection) Ordinance, 1982"; and "Bangladesh Oceanographic Research Institute Act, 2015" deals with few areas of the blue economy. Ironically, the provisions of the "United Nations Convention on the law of the sea (UNCLOS)" and the "International Convention for the Prevention of Pollution from Ships (MARPOL)" are overlooked in the existing laws. The "Bangladesh Biodiversity Act, 2017" and "Wildlife (Conservation and Security) Act, 2012" somehow cover the obligations of the "Convention on Biological Diversity (CBD)" and "Aichi Biodiversity Targets." But these laws were enacted for eyeing on terrestrial ecosystems. Bangladesh is a signatory country of approximately 45 international treaties for ensuring sustainability, nature conservation, and environmental justice (Rahman, 2021c). "Bangladesh Environment Court Act 2010" does not directly recognize ordinary people's rights, and the Court's jurisdiction is unclear (Rahman, 2021c).

\subsection{Allocation of business at the Policy level}

The respondents identified numerous actors having stakes in marine resource management (Table 3). The relevant businesses were scrutinized from the "Rules of Business, 1996" (Cabinet, 2017). The mandates of recently formed MAU have not been included in the business allocation of MOFA. MOS plays a crucial role in administering maritime transportation where its apical business is 'port,' a single word without further clarification that can denote various ports, including spaceport. The clear mandates of MOFL could not clear deadlock over fisheries management as its counterpart MOEF is entrusted with a highly ambiguous mandate. Environment and ecology can be applied to a broader range from benthic to avian ecology. Climate change is absent in the business of MOEF despite its presence in the nomenclature of this ministry.

$$
\text { Table } 3
$$

Allocations of business for the ministries/division related to marine resource management in Bangladesh (Cabinet, 2017)

\begin{tabular}{ll}
\hline $\begin{array}{c}\text { M/D } \\
\text { MOFA }\end{array}$ & \multicolumn{1}{c}{\begin{tabular}{c}
\multicolumn{1}{c}{ Allocation of business } \\
Boundary and territorial treaties; piracies and crimes committed \\
on the high seas, and administrative zonation
\end{tabular}} \\
MOFL & $\begin{array}{l}\text { Aquaculture including pearl culture, marine fisheries, deep-sea } \\
\text { fisheries, and shrimp culture in the coastal areas }\end{array}$ \\
MOS & $\begin{array}{l}\text { Ports, maritime shipping, navigation, controlling offense on high } \\
\text { seas; marine pollution from ships and crafts; registration and safety } \\
\text { administration of fishing vessels; marine search and rescue }\end{array}$ \\
MPEM & $\begin{array}{l}\text { Energy, petroleum, natural gas, mineral resources, and geological } \\
\text { survey } \\
\text { Environment and ecology; environmental pollution; conservation } \\
\text { of forests; protection of wild birds and animals; and establishment } \\
\text { of sanctuaries }\end{array}$ \\
MOEF
\end{tabular}




\begin{tabular}{|c|c|}
\hline MOCAT & Legislation relating to tourism and registration of travel agencies \\
\hline$I S D$ & Internal and border security \\
\hline$M O D$ & $\begin{array}{l}\text { Meteorological observations, hydrographic surveys, and } \\
\text { preparation of navigational charts }\end{array}$ \\
\hline MOST & Biotechnology and oceanographic science \\
\hline Mincom & $\begin{array}{l}\text { Matters related to export including treaties, agreements, } \\
\text { protocols, and conventions bearing on trade with other countries }\end{array}$ \\
\hline MODMR & $\begin{array}{l}\text { Issues related to risk reduction, emergency response management, } \\
\text { relief management, rehabilitation, safety net programs }\end{array}$ \\
\hline$L G D$ & $\begin{array}{l}\text { Development of rural water supply, sanitation and sewerage } \\
\text { system; taking poverty reduction program; and promoting } \\
\text { entrepreneurship development }\end{array}$ \\
\hline MOA & Regulating agricultural inputs \\
\hline Minland & Issues related to rights in and over land and water \\
\hline Moind & Matters related to the industry, salt industry \\
\hline GED & $\begin{array}{l}\text { Geographical Information System (GIS) platform; the national focal } \\
\text { point of renewable sources of energy }\end{array}$ \\
\hline MSW & $\begin{array}{l}\text { Community development with particular emphasis on the } \\
\text { disadvantaged segment of the society }\end{array}$ \\
\hline MOWR & $\begin{array}{l}\text { Land reclamation and estuary control; controlling salinity and } \\
\text { desertification; hydrological survey }\end{array}$ \\
\hline Moedu & Matters related to public universities \\
\hline
\end{tabular}

Instead, MODMR is entrusted with a transparent mandate like risk reduction, emergency response. The business allocation did not strengthen the footings of MOCAT in overseeing blue tourism as it is mandated to deal with tourismcentric legislatures. The Mind has been empowered to regulate the salt industry, a piece of the marine industry though it was supposed to be the nodal ministry of developing maritime industry. Being a focal point of renewable energy sources, GED has coincided its mandate with the parental MOPMR dealing with energy.

MOST deals with the matters associated with biotechnology and oceanographic science, but simultaneously, Moedu is mandated for technical education and research. On the other side of the coin, the "Bangladesh Oceanographic Research Institute Act 2015" enabled the "Bangladesh Oceanographic Research Institute" to control and coordinate all marine research. Bangabandhu Sheikh Mujibur Rahman Maritime University (BSMRMU), the only earmarked university, is administered by the $A F D$. Several public universities have marine-related faculties, departments, and disciplines which follow the guideline of Moedu. Bangladesh Marine Fisheries Academy, a MOFL-run training institute, was established to prepare graduates for marine fisheries that currently offer a bachelor's degree in nautical and marine engineering with higher interests. As MOFL is not entitled to issue a Continuous Discharge Certificate, the nautical science and marine engineering departments' cadets must collect MOS certificates. With this, Bangladesh Marine Academy's unique role, a subordinate of MOS in preparing mariners (nautical and engineering), has been fizzled out. Both these training institutes are affiliated with BSMRMU through sidestepping Moedu and MOST.

$\angle G D, M S W$, and MODMR work for the development of the coastal community without maintaining demarcated boundaries. Interestingly, the role of local government bodies in managing natural resources has been endorsed in its mandate. Hence, the participation of local government in marine and coastal resource management is in the darkness.

It is revealed that the fragmented legal framework and ambiguities in business allocation resulted in jurisdictional overlapping in almost all areas of resource management (Figure 2). Therefore, the institutional framework for coastal and marine resource management is characterized by a complex arrangement. The study found many public institutes in
Bangladesh regulate the blue economy and environmental protection, but their mandates are not clearly defined either in the legal or institutional framework.

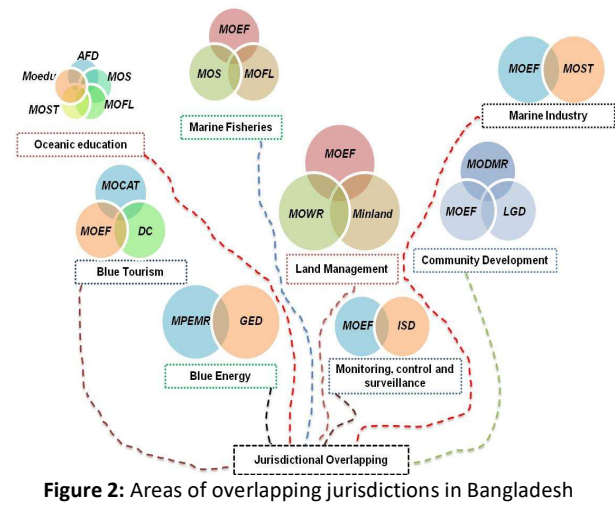

The jurisdictional overlapping leads to a conflict of interest, poor coordination, lack of cohesion, and even rivalry, which are the major pitfalls and bottlenecks in harnessing marine resources in Bangladesh (Figure 3). Very often, everybody's business turns into nobody's business.

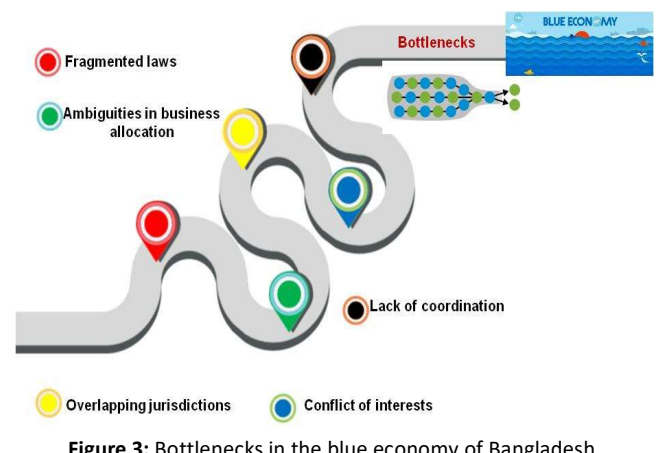

Figure 3: Bottlenecks in the blue economy of Bangladesh

It was argued that poor coordination and integration mechanisms exist among various stakeholders, neither from the policy level to the implementation level. There are few institutions established by the legal provisions for regulating the marine and coastal resources. The vagueness in the allocation of business in determining the authority created obstacles in developing effective coordination, hindering further blue growth. The absence of formal institutional mechanisms and poor coordination among public departments also caused marine living resources degradation (Rahman et al., 2020; Rahman and Alam, 2020). The fisheries resources are managed by disconnected agencies, causing competition and conflict of interests among different departments (Hossain et al., 2014; Alam et al., 2021). The sectoral, temporal, and spatial marine governance is neither supported by the legal nor institutional framework resulting in poorly functional marine governance. Hussain et al. (2017) reported that lack of coordination between and among the players negatively impacted marine trade and commerce, blue tourism, exploration of minerals, marine industries, sustainable marine fisheries, conservation, and social welfare. The coastal and maritime tourism in Bangladesh faces enormous challenges due to poor coordination and integration among different sectors (Rahman, 2021b; Rahman 2020b). The multi-layered authorities generate miserable sufferings for the artisanal fishers (Alam et al., 2021). Sarker et al. (2018) revealed that along with government functionaries, academic institutions, NGOs, and think tank organizations should be the critical stakeholders in marine regulation. 


\subsection{Governance at the implementation level}

Andharmanik: Andharmanik (the ruby of the dark), a hidden treasure trove in the Sundarbans mangrove, is characterized by a fresh-brackish swamp and intercepted by four rivers: the Shela, Kharma, Baleshwar, and Chechang. This area is earmarked as a dolphin sanctuary that is lacking tourist amenities. The Chandpai range of Forest Department manages this tourist spot's diverse plant ecosystem and herds of wild spotted deer.

Nilkamal: Despite the absence of tourist facilities, abundant spotted deer, Bengal Tiger, Marsh Crocodile, Rhesus Monkey, Peacock Turtle, Red Junglefowl, and rare birds has heightened the natural beauty of Nilkamal (blue lotus), a highly famous tourist spot in Bangladesh. Similarly, it is regulated by the Khulna range of the Forest Department.

Jamtola Beach: Jamtola (under the blackberry tree) is located in the East Wildlife Sanctuary of the Sundarbans mangrove, an exciting tourist spot. The array of littoral vegetation has enriched this beach, an exact location for watching the realistic view of sunrise and sunset over the sea. A nearby watchtower is considered the only tourist facility for this beach controlled by the Shoronkhola range of the Forest Department.

Mongla Port: The port is managed by a port authority comprised of the Chairman (Chief Executive) and three members under MOS's control. The Standing Committee on Ministry of Shipping, lead by Members of Parliament, monitors the authority's activities simultaneously. The board is entitled to formulate a policy of the administration, operation, and development.

Lalkakrar Char: Lalkakrar Char (shoal of red crab) is about five km east from Kuakata's main beach point under Patuakhali districts, an attractive place for thousands of nature lovers. These little mermaids (red crabs) come out of the residing holes during low tide turning the beach into a red carpet. The Tamarix stands beside the beach makes a red-green nexus at that time. The conflict of interest is absent in this underdeveloped beach apart from tourism amenities.

Laboni beach: This is the part of the world's longest natural sandy beach (125 kilometers), the most popular tourist spot of Bangladesh, which remains crowded by thousands of visitors over the year. The restaurants, resorts, cottage, and lobster's market are managed by the private sector fragmentally. With the help of Bangladesh Tourist Police, the district administration, Cox's Bazar ensures safety for the tourists. There is a lack of specific authority empowered by the law responsible for spatial planning, day-to-day maintenance, development of tourist facilities, and sustainability.

Cox's Bazar-Teknaf Marine Drive: The longest marine drive road in the world is surrounded by a hilly evergreen forest on one side and blue marine water on another side. On an 80 KM long road, few substandard restaurants are available in Inani and Himchhori beach points; hence, it could not be ideal for tourists, notably foreigners. Bangladesh Army, Bangladesh Police, and Bangladesh Border Guards have checking points at intervals, and hence, it is quite tricky to find the actual authority of this drive.

The study reveals that the local government bodies play a perplexing role in marine and coastal resource management. On the other hand, the active participation of the community has not been embraced yet. Not only community-based ecotourism but also sustainable tourism is impoverished. Both the existing legislative and institutional mandates do not endorse the community's role in the decision-making and implementation processes. Due to centralized and bureaucratic management systems (Giessen et al., 2016), the Public Departments could not ensure the full participation of the community and other stakeholders in natural resource management (Millat-e-Mustafa, 2002; Rahman, 2021a).

\subsection{Fishers' Challenges in Bangladesh}

The fishers identified piracy as the greatest threat indicating futile legal and institutional arrangement, noncompliance with the laws, laxity in enforcement, and ineffective MCS (Figure 4). Due to a lack of high sea governance, foreign pirates frequently enjoy hegemony in the sea. The fish stock is declining in the estuary and territorial water for the commercial fishers' ascendancy and destructive fishing, albeit prohibited per "National Fisheries Policy 1998". Shamsuzzaman and Islam (2018) revealed that this policy is not implemented due to DOF laxity. Sometimes, the fishers suffer tremendous hassles, including red-tapism and bribery, at fishing vessel registration. The formal banking system does not offer the fishers' loans though it is the constitutional right to be treated equally as the country's permanent residence. It can be argued that DOF could not establish a coordination mechanism with the Financial Institutions; thus, the fishers depend on Mahajan (local moneylenders). They pay back a $100 \%$ interest rate, which propels vulnerability and poverty. This local credit system is notoriously known as Dadan.

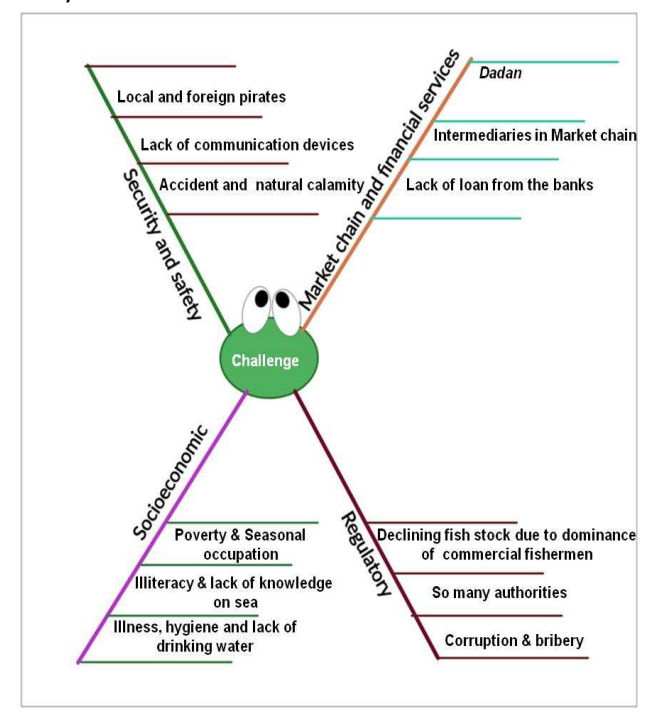

Figure 4: Spider diagram showing the challenges of artisanal and small scale fishers in Bangladesh

The fishers found seven groups of intermediaries in the fish market chain: collector, majhi (the Captain of the boat), Chhoto Mahajan (small moneylender), Boro Mahajan (big moneylender), Aratdars (a commission agent for stocking), wholesaler, and retailer (Figure 5). Jointly Chhoto Mahajan and Boro Mahajan make the highest profit, which is equal to more than $50 \%$ of the retail price, while the other groups make 25 $30 \%$. As the fishers cannot sell the harvested fish to the consumers directly, they are bound to be happy with $20-25 \%$ of retail prices. In Bangladesh, the agricultural market and supply chain are distorted and fragile, controlled by intermediaries (Alam et al., 2021). Before going to the sea, fishers collect weather forecasts as there is no mobile phone network coverage there, while a segment depends on only radio. 


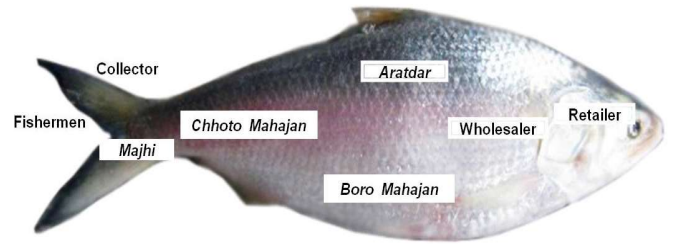

Figure 5: Intermediaries groups in the fish market chain of Bangladesh

\section{Recommendations}

\subsection{Legal reforms}

Bangladesh can enact sectoral laws to abolish jurisdictional overlapping and conflict of interests. Beforehand, a law commission can be formed to identify the conflicting issues in the segmented laws. The new laws should incorporate international commitments and obligations and the problems of sustainability and conservation.

\subsection{Reallocation of business}

After necessary legal reforms, the business for a few ministries and divisions should be reallocated to downsize the number of actors to ensure that anyone's business is not everyone's business.

\begin{tabular}{l|l|}
\hline MD & \multicolumn{1}{|c}{ Reallocation of business } \\
\hline MOFL & Marine and coastal fisheries including protected areas, mariculture, pearl culture, brackish shrimp culture \\
\hline MOEF & Terrestrial forest resources, tacking climate change, the focal point of land-based pollutions \\
\hline MOS & Sea ports, maritime shipping, navigation, rescue $\&$ safety, enforcement of sea laws, marine-based pollution \\
\hline Moind & Marine industries including shipyard, ship recycling, marine optical fiber and tourism \\
\hline Mincom & Marine trade and commerce \\
\hline MPEMR & Exploration and mining for minerals, blue energy \\
\hline Moedu & Training, education and research \\
\hline MOST & Biotechnology, sea weeds, the focal point of oceanographic science \\
\hline MOFA & The focal point of high sea governance \\
\hline LGD & The focal point of local governance \\
\hline ISD & The focal point of monitoring, control and surveillance \\
\hline
\end{tabular}

Figure 6: Proposed business reallocation for key ministries/divisions of Bangladesh

By considering the chaotic conditions in living resource management, marine industries, blue energy, maritime security, coastal management, and local governance, mandates' reallocation has become inevitable. Hence, the study recommends revising the "Rules of Business, 1996" (Figure 6).

"The Maritime Affairs Unit (MAU)" working under the "Ministry of Foreign Affairs" can be graduated to a separate and independent ministry to establish effective coordination with other ministries. A national and sectoral statutory body, councils, and boards can be formulated. In addition, they will help different ministries in taking appropriate development projects and management schemes. A National Marine Education and Research Committee are highly warranted to integrate research works and coordinate among researchers. MOFA should be entitled to be the focal point of high sea governance following UNCLOS so that it can coordinate with other marine states shared by the Bay of Bengal. The Bangladesh Navy and Coast Guard's roles should be clearly defined to accelerate the Monitoring, control, and surveillance (MCS). LGD should be empowered to oversee the local governance for natural resource management.

\subsection{Policy interventions}

Bangladesh needs a comprehensive separate marine policy highlighting sectoral priority areas, coordination mechanism, and community welfare. Without the community's active participation and wholehearted support, it will be challenging to ensure any programs' sustainability. Either co- management or ecosystem-based management can ensure participatory governance, conservation, and, finally, sustainability. The Department of Agricultural Extension achieved positive outcomes by forming Village-based organizations in the rural areas (Rahman and Akter, 2020). DOF can replicate this concept among artisanal fishers. The commercial fishers should be motivated to harvest pelagic fishes and introduce high sea fishing to establish artisanal and smallscale fisher's rights and protect further decline of fish stock in the estuary and territorial water. The Bangladesh coast guard's proactive role can control piracy and robbery in the sea and coastal areas. The marketing system can be modernized by clearing the intermediaries group from the market chain. DOF should coordinate with the formal banking system to disburse loans for the community people, which are warranted to stop the local lenders' (Mahajan) monopoly business and improve the socio-economic conditions. The departments, notably DOF, should be equipped with modern logistics and a sufficient workforce. Bangladesh Parjatan Corporation (BPC), a statutory board under the Ministry of Civil Aviation and Tourism, is tasked to promote the country's tourism industry. The policymakers should take initiatives to improve the quality of the restaurants and hotels of BPC to attract more tourists. Community-based tourism helps in employment generation and branding of local products and culture. Fish telemetry technology or community radio for fishers could be installed in the coastal area to forecast weather and provide fishing guidelines.

Strong cohesion of the public departments, researchers, academia, non-government organizations, private sectors, training institutes, research institutes, and the community can maximize the benefit without ecological degradation. The coordination among marine states is essential for conservation and tackling climate change. One country's conservation initiative may be jeopardized by the over-extraction and destructive activities of other countries. For optimizing the benefits, the marine stakeholders need to consider the undeniable role of the land managers.

Considering the environmental degradation caused by increased salinity (Rahman 2020a), Bangladesh should avoid brackish shrimp culture. The alternative income generations like crab caging, giant freshwater prawn (Macrobrachium rosenbergii) culture, mixed prawn-rice culture, nypa-shrimp-crab culture, multi-trophic aquaculture, apiculture, and small entrepreneurship development may be testified to solve employment centric problems. Rahman (2020a) revealed that agroforestry in the lower saline zone might be a good income generation option.

An integrated Marine Spatial Planning (MSP) in Bangladesh is compelling to achieve various long-term ecomarine growth objectives. A complete inventory of both living and non-living resources could be done for conservation and sustainable use beforehand. Multi-disciplinary sustainable marine resource management requires highly professional human resources and motivated researchers. The country should develop a large number of skilled and well equipped human resources in the field of marine science, marine fisheries, biotechnology, climate change, marine dynamics, marine engineering, ocean acidification, maritime trade, offshore mining, naval architectural engineering, marine geological aspect, marine environment, and ecosystem science, etc. Further research should be carried out on policy analysis, stock assessment, potential resources, ecosystem services, biodiversity conservation, ocean pollution, and climate change. 


\section{Acknowledgment}

The author must be grateful to Dr. M Aslam Alam, ExRector (Ex-senior Secretary to the Government of Bangladesh), and Md. Rakib Hossain ndc, current Rector (Secretary to the Government of Bangladesh), Bangladesh Public Administration Training Centre, for their wholehearted support in accomplishing this work.

Fund: Bangladesh Public Administration Training Centre funded this research project.

\section{Bibliography}

Ahmed, M.H. and Rahman, M.M. 2020. An assessment of the blue economy opportunities of Bangladesh within the Exclusive Economic Zone (EEZ), Paper presented at the 7th International Conference on Public Administration and Development, 5-8 February, BPATC, Savar, Dhaka, Bangladesh.

Ahmed, N. and Glaser. M. 2016. Can 'Integrated Multi Trophic Aquaculture' adapt to climate change in Coastal Bangladesh?" Ocean and Coastal Management, 132: 120-131.

Alam, S., Rahman, M.M. and Arif, A.A. 2021. Challenges and opportunities in artisanal fisheries (Sonadia Island, Bangladesh): The role of legislative, policy and institutional frameworks. Ocean \& Coastal Management, 201, 105424, https://doi.org/10.1016/i.ocecoaman.2020.105424.

Ali, M., David, M.K. and Lai, L.C. 2013. Using the Key Informants Interviews (KIIs) technique: A social sciences study with Malaysian and Pakistani respondents. Man. and Society, 24: 131-148.

Bdgov. 2020. National Web Portal, The Government of the People's Republic of Bangladesh. https://bangladesh.gov.bd/index.php.

Bengtsson, M. 2016. How to plan and perform a qualitative study using content analysis", Nursing Plus Open, 2: 8-14.

Berg, B.L. 2009. Qualitative research methods for the social sciences, 7th ed., Allyn \& Bacon: Boston.

Billah, M.M., Kader, M.A., Siddiqui, A.A.M., Mahmud, S.S. and Khan, M.R. 2018. Studies on fisheries status and socioeconomic condition of fishing community in Bhatiary coastal area Chittagong, Bangladesh. Journal of Entomology and Zoology Studies, 6 (6): 673-679.

Cabinet. 2020. Rules of Business 1996 (Revised up to April 2017), Cabinet Division, Government of the People's Republic of Bangladesh.

DiCicco-Bloom, B. and Crabtree, B. F. 2006. The qualitative research interview. Medical Education, 40 (4): 314-321.

Dooley, K.J. 2016. Using manifest content analysis in purchasing and supply management research. Journal of Purchasing and Supply Management, 22 (4): 244-246.

FAO. 2014. Opportunities and Strategies for Ocean and River Resources Management. Food and Agricultural Organization of the United Nations, Background paper for preparation of The 7th Five Year Plan, Dhaka, Bangladesh.

Giessen, L, Sarker, P.K and Rahman, M.S. 2016. International and domestic sustainable Forest Management policies: Distributive effects on power among state agencies in Bangladesh. Sustainability, 8: 335.

Gill, P., Stewart, K., Treasure, E., and Chadwick, B. 2008. Methods of data collection in qualitative research: interviews and focus groups. British dental journal, 204 (6): 291295. https://doi.org/10.1038/bdj.2008.192.
Giménez, L, Jolliffe, D and Sharif, I. 2014. Bangladesh, a Middle Income Country by 2021: What Will It Take in Terms of Poverty Reduction? World Bank, Washington DC.

Harrison, H., Birks, M., Franklin, R. and Mills, J. 2017. Case Study Research: Foundations and Methodological Orientations. Forum: Qualitative Social Research, 18 (1), Art. 19. http://dx.doi.org/10.17169/fqs-18.1.2655.

Hasan, M.M, Hossain, B.H.S Alam, M.J, Chowdhury, K.M.A, Karim, A.A and Chowdhury, N.M.K. 2018. The Prospects of Blue Economy to Promote Bangladesh into a MiddleIncome Country. Open Journal of Marine Science, 8: 355-369.

Hussain, G.M, Failler, P, Al Karim, A and Alam, M.K. 2017. Review on opportunities, constraints and challenges of blue economy development in Bangladesh. Journal of Fisheries and Life Sciences, 2 (1): 45-57.

Islam, M.M and Shamsuddoha, M. 2018. Coastal and marine conservation strategy for Bangladesh in the context of achieving blue growth and sustainable development goals (SDGs). Environmental Science and Policy, 87: 4554.

Islam, M.M. 2012. Poverty in small-scale fishing communities in Bangladesh: context and responses. PhD Thesis, University of Bremen, Germany.

Krippendorf, K. 2004. Content Analysis: An Introduction to its Methodology, Sage Publications, Beverly Hills, CA.

Millat-e-Mustafa, M. 2002. A review of forest policy trends in Bangladesh, Bangladesh Policy Trend Report (114121).

Neuendorf, KA. 2002. The Content Analysis Guidebook, Sage publications.

Ørngreen, R. and Levinsen K. 2017. Workshops as a Research Methodology. The Electronic Journal of eLearning, 15 (1): 70-81.

Rahman, M.M. 2021a. Assessing the progress and pitfalls of the Ministry of Environment, Forest and Climate Change in achieving SDGs in Bangladesh. Bangladesh Journal of Public Administration (BJPA), 29(2). https://dx.doi.org/10.2139/ssrn.3773496.

Rahman, M.M. 2021b. Inbound tourism in Bangladesh: Trend of competitiveness. Bangladesh Journal of Public $\begin{array}{lll}\text { Administration } & \text { (BJPA), }\end{array}$ https://dx.doi.org/10.2139/ssrn.3773482.

Rahman, M.M. 2021c. Can ordinary people seek environmental Justice in Bangladesh? Analyzing through the lens of legal, policy, and institutional framework. Bangladesh Journal of Public Administration (BJPA), 29(2). https://dx.doi.org/10.2139/ssrn.3773485.

Rahman, M.M., and Alam, M.A. 2020. Regulatory and Institutional framework for the conservation of coral reefs in Bangladesh: A Critical Review. In Alam, M.A., Alam, F. and Begum, D. (Eds.), Knowledge Management, Governance and Sustainable Development: Lessons and Insights from Developing Countries. India: Routledge, https://dx.doi.org/10.2139/ssrn.3794550.

Rahman, M.M., and Akter, M. 2020. Effectiveness of VillageBased Organization (VBO) in improving the livelihood of the rural community in Bangladesh, Bangladesh Journal of Public Administration (BJPA), 28(2): 27-37. https://dx.doi.org/10.2139/ssrn.3759175.

Rahman, M.M. 2020a. Impact of increased salinity on the plant community of the Sundarbans Mangrove of Bangladesh. Community Ecology, 21:273-284, DOI: 10.1007/s42974-020-00028-1. 
Rahman, M.M. 2020b. Achieving Sustainable Development Goals in Bangladesh: An Organizational Analysis. SSRN Electronic Journal, http://dx.doi.org/10.2139/ssrn.3779081.

Rahman, M.M., Alam, M.A., Rahman, M.M., Mamun, M. and Alam, A. 2020. Challenges of Artisanal Fishermen: A Case Study from Sonadia Island, Bangladesh. In Alam, M.A., Alam, F. and Begum, D. (Eds.), Knowledge Management, Governance and Sustainable Development: Lessons and Insights from Developing Countries. India: Routledge. https://dx.doi.org/10.2139/ssrn.3773504.

Rahman, M.M. 2018. The pros and cons of co-management: a case study from the Sundarban Delta", a paper presented at World Social Science Forum 2018, 25-28 September, Fukuoka, Japan. DOI: 10.5281/zenodo.4541022.

Rahman, M.M., Nishat, A. and Vacik, H. 2009. Anthropogenic disturbances and plant diversity of the Madhupur Sal forests (Shorea robusta C.F. Gaertn) of Bangladesh", International Journal of Biodiversity Science and $\begin{array}{llll}\text { Management, } & 5 & \text { (3): } \quad 162-173 .\end{array}$ https://doi.org/10.1080/17451590903236741.

Sarker, S, Bhuyana, M.A.H, Rahman, M.M, Islam, M.A, Hossain, M.S, Basakc, S.C and Islam, M.M. 2018. From science to action: Exploring the potentials of Blue Economy for enhancing economic sustainability in Bangladesh, Ocean and Coastal Management, 157: 180-192.

Shamsuzzaman, M.M and Islam, M.M. 2018. Analysing the legal framework of marine living resources management in Bangladesh: Towards achieving Sustainable Development Goal 14. Marine Policy, 87: 255-262.

Shamsuzzaman, M.M., Islam, M.M., Tania, N.J., Al-Mamun, M.A., Barman, P.P. and Xu, X. 2017a. Fisheries resources of Bangladesh: Present status and future direction. Aquaculture and Fisheries, 2: 145-156.

Shamsuzzaman, M.M, Xiangmin, X, Islam, M.M, Alam, M.W and Karim, E. 2017b. Sustainable Marine Fisheries Resources of Bangladesh: A Strategic Response for Economic Security. Indian Journal of Geo Marine Sciences, 46 (4): 757-765.

Spencer, L, Ritchie, J and O'Connor, W. 2003. Analysis: practices, principles and processes. In J. Ritchie \& J. Lewies (Eds.), Qualitative Research Practice: A Guide for Social Science Students and Researchers, Sage Publications Ltd, London, pp. 199-218.

Stuckey, H. L. 2013. Three types of interviews: Qualitative research methods in social health. Journal of Social Health and Diabetes, 1 (2): 56-59. https://doi.org/10.4103/2321-0656.115294.

Zhang, L.E. and Guttormsen, D.S.A. 2016. Multiculturality' as a Key Methodological Challenge during In-depth Interviewing in International Business Research. Cross Cultural \& Strategic Management, 23 (2). https://doi.org/10.1108/CCSM-07-2014-0084. 